\title{
Verbal Behavior Analysis as a Diagnostic and Psychopharmacological Strategy for Differentiating Paranoid and Disorganized Schizophrenics
}

\author{
Frederic Verhaegen and Michel Musiol \\ Nancy Université (Université Nancy 2) \\ Laboratoire de Psychologie de l'Interaction et des Relations Intersubjectives, \\ MSH Lorraine \\ France
}

\section{Introduction}

Schizophrenia is no doubt one of the most controversial psychotic disorders when it comes to describing the symptomatological characteristics (or syndrome groups) that define it. It has no syndrome-specific pathognomonic sign, and its etiology remains poorly understood (Andreasen \& Carpenter, 1993; Tsuang, 2000). A century of inquiries supported by considerable progress, especially recent advancements in electrophysiology, imaging, molecular biology, and even cognitive psychology (evolutionary psychology among others), have not yet supplied the needed answers, in such a way that coming up with a single definition of "schizophrenia" is still impossible. Even today, then, this pathology remains an ill-defined reality. Many studies have suggested that one problem with schizophrenia is its heterogeneity (Heinrichs, 1993), an idea supported not only by the discovery of its multiple clinical manifestations but also and especially because it is difficult to find characteristics or features that are shared by all individuals diagnosed with this disease (Chapman \& Chapman, 1989; Goldstein, 1990; Heinrichs, 1993).

In this chapter, we will not address the issue of the potential cognitive or neuropsychological processes underlying the symptoms of schizophrenia. Whatever they may be, we believe that the pathology will necessarily be manifest in interactive and discursive settings, whether experimental or clinical; and we hypothesize accordingly that under certain conditions - at least in the natural conditions of language use - the verbal behavior of schizophrenics is likely to reflect the specificities of the disease (Musiol \& Trognon, 2000). Locating and analyzing these specificities, if there are any, should therefore improve diagnosis strategies in the middle term.

Based on our view that verbal interaction is the "natural locus of symptom expression" (Trognon \& Musiol, 1996), we propose a methodology for analyzing verbal interaction that is inspired by both pragmatics and cognitive psychology. Our aim is, firstly, to detect discourse and dialogue discontinuities as objectively and "decisively" as possible (by "decisively", we mean that there is a high probability of finding pathological dysfunctioning 
behind the pathological behavior). Then we look at the potential relationship between these discontinuities and the syndrome's specificities, and at a more general level, we discuss how they relate to the question of incoherence. Finally, we show that our pragmatic, cognitive, and formal methodology for dialogue analysis (Musiol, 2002; Musiol \& Rebuschi, 2011) enables us to better specify and better differentiate between the various schizophrenic syndromes.

\section{Grasping the symptomatological characteristics of schizophrenia}

Clinical research on schizophrenia has been making significant progress for nearly thirty years now. In the 1970's and 80's, inquiries into the well-foundedness of the classification into subtypes (paranoid, disorganized, catatonic, etc.) proposed in clinical psychiatry gave way to other models for describing the disease (Andreasen, 1979a; 1984; Andreasen \& Olsen, 1982; Crow, 1980; Liddle, 1987). The results of these studies, although growing in number, were contradictory, however, so their heuristic relevance was discredited to some extent. The heterogeneity of the findings led investigators to steer their research towards trying to establish more accurate criteria in view of obtaining greater homogeneity in the populations under study. The development of a number of clinical-information gathering methods, all aimed at producing more global symptom-assessment scales, is an example of this latter approach. New tools like Kay et al.'s (1987) PANSS (Positive and Negative Syndrome Scale), and Andreasen's $(1983,1984)$ SANS (Scale for the Assessment of Negative Symptoms) and SAPS (Scale for the Assessment of Positive Symptoms) became the first methods used and designed for the specific purpose of evaluating the negative and positive symptoms of schizophrenia. All of these early scales are still widely used today.

The work that produced these tools was thus based on psychometric analyses (mostly factor analyses). Schizophrenia was described first in terms of two dimensions (Andreasen, 1983; 1984; Andreasen \& Olsen, 1982; Crow, 1980) and then in terms of three (Liddle, 1987): positive (or productive), negative (or deficient), and disorganized, characterized by formal thought disorders (impoverished and incoherent discourse). In addition, schizophrenics frequently suffer from cognitive deficits affecting attention, memory, and executive functions. The impairment is sometimes massive and is relatively well correlated not only with negative-symptom severity, but also, although to a lesser extent, to positive-symptom severity (Berman et al., 1997; Harvey et al., 1996). These new orientations proved promising and sparked considerable interest, partly due to their satisfactory degree of diagnostic and statistic validity, grounded in particular on their good inter-judge reliability rates. Another advantage of this type of clinical scale for assessing schizophrenic symptomatology is that these psychometric instruments have generally been deemed very useful in evaluating the effectiveness of neuroleptic medication.

\subsection{Psychometric approach to communication disorders in schizophrenia}

The idea that language abnormalities pervade the discourse of schizophrenic patients is now largely acknowledged by the scientific community. However, although language and communication disorders are among the most widely studied, they are hardly ever examined in an interaction context. Taking a classical clinical approach, Andreasen (1979a, $1979 b$ ) drew up an extensive inventory of these disorders based on the symptom-assessment scales she developed for describing the language-related anomalies specific to schizophrenic 
discourse. Moreover, her work is still valid today (Bazin et al., 2002; Bazin et al., 2005; Docherty et al., 2003; Liddle et al., 2002; Olivier et al., 1997).

Moreover, clinical observation has made a substantial contribution to describing these impairments. Right from the very first descriptions of schizophrenic symptoms, a preponderant concern was language, or even thought disorders (Bleuler, 1911; Chaslin, 1912; Kraepelin, 1971). In fact, it was in a Bleulerian perspective centered on language and communication that Andreasen designed a scale for assessing dissociation (Scale for Assessment of Thought, Language and Communication or TLC) in an attempt to make the concept of "formal thought disorder" fully operational. A such disorder is indeed a key symptom for researchers and clinicians interested in the potential complex thought disorders associated with this pathology. Note that Andreasen's TLC was recently translated into French and validated by Bazin (Bazin et al., 2002).

Studies attempting to gain finer insight into the symptomatology of schizophrenia via a clinical approach continue to grow in number. It has become clear, however, that although these concepts - "formal thought disorder", "incoherence", "disorganized thought" - have been addressed in terms of their relationship to language problems, little research has been conducted to look into how they are related to verbal interaction, that is, interaction in the "natural context" where these phenomena occur (Trognon \& Musiol, 1996). In our minds, analyzing this context is a prerequisite for relating these language behaviors to the specific communication, language, and thought abnormalities of these individuals, and in the end, for relating the "incoherent" behaviors rooted in these problems to potential dysfunctions of the underlying cognitive processes, themselves based on the language faculty (Hauser et al., 2002), mental logic (Rips, 1995), reasoning (Politzer, 2002), dialogue (Musiol \& Rebuschi, 2011), and the interleaved processes required to manage several of these subcomponents. This brings us directly back to the question of what unit should be used to analyze these phenomena. We will address this question in the next section.

\subsection{Features of discontinuity in schizophrenic verbal interaction (pragmatic, cognitive, and dialogical approach)}

Instruments based on "quantification", including psychometric scales, do not paint an accurate picture of the cognitive specificities of schizophrenic language and communication disorders. Such instruments are developed using a static type of methodology that is hardly compatible with the naturally dynamic character of communication. In addition, concepts like "incoherence" and "formal thought disorders" are only defined in terms of the items included in the scales (Andreasen \& Grove, 1986; Bazin et al., 2002), i.e., solely in terms of the overt behaviors assumed to be associated with the concepts, without reference to the utterance and discourse contexts from which the behaviors arise, nor to the psycholinguistic and/or inferential types of cognitive processes upon which the behaviors rest.

In parallel with the clinical and psychometric approach to schizophrenic communication disorders, a pragmatic and linguistic type of approach began to develop in the 1970's. Unlike the preceding approach, this approach studies the language and communication "disorder" in situ, while putting as much emphasis on the speech act as on the syntacticsemantic structure of the utterance and the contextual dimension of the uttering process, grasped in context (Chaïka, 1974; Fromkin, 1975). This means that nearly 20 years before the 
emergence of the dynamic and resolutely conversational and dialogical approach (Trognon, 1992), the goal had already become to grasp more than just the schizophrenic language disorder itself, but also and especially the impaired way in which these individuals use language in a communication setting (whether in a clinical interview, a therapy session, or an ordinary conversation). Within the past two or three decades, few researchers have challenged the idea that the greatest, if not one of the most important, difficulties of schizophrenic patients lies at the pragmatic level (making use of signs in communication contexts) (Andreasen et al., 1985; Chaïka, 1974, 1990; Frith, 1992; Fromkin, 1975; McKenna \& Oh, 2005; Rochester \& Martin, 1979; Widlöcher \& Hardy-Baylé, 1989). Yet few investigators have attempted to develop tools suited to the ways these disorders are expressed during verbal interaction, i.e., tools that take the process-based, dynamic nature of interaction into account.

By focusing on the properties of conversations involving a psychiatric patient, we propose to develop descriptive, objective, and increasingly "decisive" models of the signs of schizophrenia, and thereby rise to the challenge presented by Chaïka and other linguists in the early seventies. We will do this by considering not only the utterance context of potentially incoherent speech acts, but also the dialogical context that surrounds the interview in which those acts are accomplished. Research on such conversations has provided support for the hypothesis that schizophrenic patients exhibit syndrome-specific impairments at the discourse and communication levels, and more specifically, alterations that affect the psychocognitive principles governing language use (Grice, 1975; 1987; Musiol, 2004; Sperber \& Wilson, 1995).

Studies conducted in the pragmatic research trend of cognitive psychopathology since the early 1990's (Musiol, 1992; Trognon, 1992) have shown in this vein that the expression modes of a disorder -- here, schizophrenia -- are largely dependent upon the characteristics of the interaction, particularly the possibility conditions of verbal communication. We thus propose to grasp discourse and dialogue disorders' using a discontinuity-analysis model designed to account for schizophrenic language use and its interrelationships both with the patients' discourse and with their conversational behavior as it is manifested in particular in the turn-taking process. The many properties of verbal interaction -- turn-taking, reciprocity, the hierarchical and dynamic organization of its constituents, and the interlocutionary roles the communicating subjects occupy in the turn-taking process (initiator/speaker versus reacting-partner/listener) -- should all be seen as factors likely to have an impact on our understanding of the significance of a symptom (Musiol, 2002), in such a way that the interlocution can be regarded as the natural locus of expression of psychopathological phenomena (Trognon \& Musiol, 1996). Because of its specific properties and the constraints it imposes on the interlocutors' behavior, then, the conversational transaction is the perfect place, methodologically speaking, for observing certain interpretive and inferential processes and their potential dysfunctioning.

Below we present the premises of our investigation strategy, based for the time being on a dialogical and pragmatic type of analysis and aimed at bringing any such dysfunctions and incongruities to the fore. Our task here is to build a predictive model describing the properties of the inferential processes underlying certain forms of incoherence in dialogue, which in our case, should show up in the behaviors that schizophrenic and "normal" interlocutors are led to adopt. 


\subsubsection{Discontinuity and verbal Interaction}

The idea, then, is to build a dialogical and pragmatic model capable of accounting for the dynamic properties of verbal-interaction sequences in which a discontinuity ${ }^{1}$ appears. The skills examined -- which belong more specifically to the field we investigate using our pragmatic, dialogical, and cognitive approach to psychopathology -- are thus related to the characteristics of the inferential processes interlocutors are led to act out in a verbal exchange, and more specifically, in a clinical interview. They are also related, among other things, to the cognitive processes used to manage the properties extracted from the various different components of the primary communication units that generate the verbal interaction. These units are elementary illocutionary acts, also called speech acts or discourse acts. On the empirical level, our research in this area over the past fifteen or so years (Musiol \& Trognon, 2000; Musiol \& Verhaegen, 2009) has enabled us to hypothesize that conversations involving a schizophrenic patient will exhibit many incongruities and discontinuities. Our studies have also led to the hypothesis that the discontinuities formally detected and delineated within a verbal interaction with a schizophrenic fall into two main categories, defined by the so-called hierarchical and functional properties of the discourse structure. Relative to this "hierarchical and functional" structure of discourse (Roulet et al., 1985), we will call the first category "non-decisive" and the second, "decisive".

The idea that discourse must be approached as a verbal interaction, at least in linguistics, dates back to the 1930's and Bakhtine (Bakhtine, 1930), but the concept of hierarchical structure itself was introduced by Pike in the late 1960's (Pike, 1967). This author incorporated the study of language (both languages and discourse) into a unified theory of the structure of human behavior. In his theory, as the author explains, any event involving human behavior (a religious service, for example) can be broken down at the first level into a certain number of constituents linked by specific functions; each constituent can in turn be broken down into lower-level constituents, and so on down until we obtain units of behavior like the utterance or the word.

In this view - and similarly to what is expressed in certain conceptions developed in the linguistics of argumentation (Roulet et al., 1985) or in the psychology of communication (Trognon, 1995; Trognon et al., 1999) - discourse (that is to say, the conversational transaction) can be seen as a "negotiation" process, which makes its structure and functioning easier to grasp, and the conversational transaction can be seen as the relevant unit of analysis. We will define conversational transactions as follows: the most elementary component is the simple or complex speech act (the illocution). Illocutions are defined as acts that apply forces to propositional content (Searle \& Vanderveken, 1985); the force defines the type of action (assertive, commissive, directive, declarative, expressive) that the speech act accomplishes, and can be described in terms of a number of properties, of which the illocutionary goal and its direction of fit are among the most important. At a more global level, conversational transactions are regular groups of structures, and structures are regular groups of exchanges and interventions. Accordingly, an exchange is the basic unit of an interlocution, where "basic" means that it is the smallest "dialogical" unit of the interaction (Goffman, 1974; Roulet et al., 1985).

From a microscopic point of view, an exchange is made up of interventions, and the minimal intervention is made up of speech acts (or illocutions). From the macroscopic point of view, exchanges and interventions are organized into structures. Some of these structures

${ }^{1}$ Here, we interpret the notion of incoherence in terms of discontinuity 
exhibit a typical organization and can be functionally interpreted as if they realized a collective intentionality. Some examples are communicating information, debating, discussing, negotiating, leading a group, making a group decision, as is conducting or participating in a clinical interview or a psychotherapy session.

\subsubsection{Properties of non-decisive discontinuity}

Earlier studies (see below) have shown that schizophrenic interlocutions (i.e., ones involving a person diagnosed as schizophrenic) exhibit many discontinuities between adjacent segments of discourse, whether at the exchange or intervention level. These discontinuities occur either when the schizophrenic patient is the second speaker and is attempting to adjust his/her reply to the interlocutor's previous intervention, or when the patient is expressing his/her train of thought as he/she accomplishes several speech acts within the same discursive intervention. We will use the term "between-intervention breaks" to refer to coherence problems or discontinuities resulting from a violation of the chaining constraints that guarantee continuity between the speaking turns of two separate interlocutors in an exchange, and "within-intervention breaks" to refer to coherence problems or discontinuities resulting from violation of between-act chaining constraints within the same intervention. Note that in discourse, there exist complex interventions that contain subparts made up of one or more embedded interaction exchanges (Roulet et al., 1985). Failure to satisfy any of these constraints, no matter what kind, suffices to produce a discontinuity. Note in addition that chaining constraints apply locally first, between adjacent speaking turns, but the possibility of embedded exchange sequences authorizes deferred constraint satisfaction (until after this type of sequence is over), which takes place farther along in the unfolding of the discourse. It is also possible to double up embedded sequences recursively (one can always make a parenthetical remark within another parenthetical remark), which means that the interlocutors must be capable of managing a recursive exchange structure (and that the formal analyst of the exchange must be able to take its hierarchical structure into account). To be exact, one must make the distinction between "proximal" breaks, which occur between adjacent interventions, and "distal" breaks, which also result from the violation of a chaining constraint, but this time between non-adjacent interventions. Although distal, these non-adjacent interventions structure the discourse, insofar as the intervention called the speaker's initiative contains the directing utterance that conveys the speaker's intended meaning, and the intervention called the listener's reactive-initiative intervention contains the directing utterance that carries the linguistic trace of the addressee's interpretation of the initial directing utterance. Failure to satisfy these distal constraints in a deferred manner -- no doubt because there is no representation of them -constitutes failure in a complex task. As such, it reflects severe disorganization of the interlocutive ability (Musiol \& Pachoud, 1999).

Below we present a non-decisive discontinuity exemplifying a between-intervention break. Example 1 ( $\mathrm{X}$ is the schizophrenic interlocutor $)^{2}$

2 Transcription conventions: (...) stands for the beginning and end of a conversational sequence; $(\rightarrow)$ stands for prolonged pronunciation of a sound of the language; $(\uparrow)$ stands for a rising intonation; $(\downarrow)$ stands for a falling intonation; (inaudible) means that the passage was inaudible (sometimes its duration is indicated); words in capitals mean that the speaker stressed the word; $+5+$ stands for a silence of five seconds. Information likely to be important for understanding and analyzing the transcription is shown in parentheses. Ambiguous passages are shown in brackets. For ethical reasons, 
V51: (...) and how do you spend your time otherwise $(\uparrow)+5+$

X52: I watch TV

V53: $\quad$ You watch TV and you watch TV where $(\uparrow)$

X54: In this room

V55: In this room here and what about when you're not here $(\uparrow)$ when you're somewhere else

X56: I was born in S (city)

V57: Yeah

X58: $\quad$ On September 20th 19xx (...)

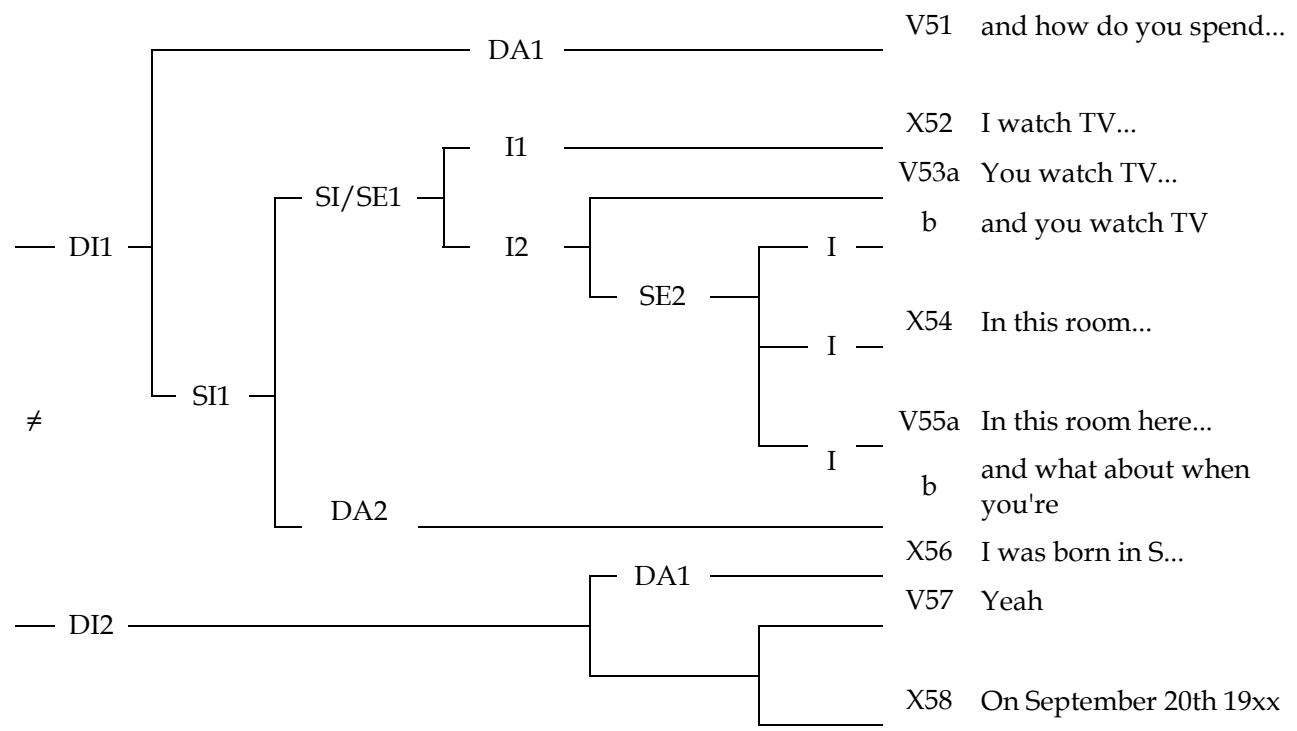

Legend. SE: subordinate exchange. I: intervention. DI: directing intervention. DA: directing act. SI: subordinate intervention. V: interlocutor V. X: interlocutor X. \#: discontinuity.

Fig. 1. Commented hierarchical diagram of Example 1.

This exchange consists of two directing interventions (I1 and I2), corresponding to two conversational contributions of two different speakers, the first by the "normal" interlocutor (hetero-initiated from the patient's point of view). This first intervention, I1, can be considered complex. It contains five speaking turns (V51 to V55), and is made up of a directing intervention (a substructure represented by intervention V51/DA1, a first-level directing act), and a subordinate structure, SI1, which takes place between X52 and V55. This subordinate intervention will be called complex too; it consists of a directing substructure V55b/DA2 (second-level directing act) and a subordinate exchange, SE1, which constitutes its subordinate part (SI) insofar as V55b retroactively subordinates this

the names of persons, places, and dates have been changed to guarantee the anonymity of all participants. 
substructure. Because the schizophrenic interlocutor's reactive-initiative intervention (I2) unfolds between X56 and X58 (with a directing constituent conveyed by X563), one can make the assumption that I1's directing component is carried by the utterance acts performed in DA1 and DA2, as a directive type of complex speech act like [DA1-DA2] would do, here, "How do you spend your time when you're not here?"

The hierarchical and functional analysis of this sequence thus ascribes X56 the status of act serving as the "initiative-interpretive reaction" to the initiating directing component, but a discontinuity appears. The break is the result of the lack of continuity here between V51/V55b (I1/DA1-DA2) and X56 (I2/DA1). By definition, we will consider discontinuities that have an effect on the exchange to consist, discursively, of a pair of adjacent interventions ( $\mathrm{Ii}, \mathrm{Ij}$ ) whose second element, $\mathrm{Ij}$, is not in a continuity relation with the intervention that precedes it (Ii) in the conversation. The first element, Ii, is seen as a source variable that imposes constraints on the second element, Ij. In Roulet et al.'s (1985) sense, the source variable, Ii, thus defines the set of all between-intervention constraints linked to a question that has a closed set of possible responses. These constraints are:

- Thematic condition: obligation to reply on the theme addressed in the question.

- Propositional-content condition: obligation to give a reply whose content is related to the question's content in an implicative, antonymic, or paraphrastic way.

- Illocutionary condition: obligation to express the content of one's reply in the corresponding illocutionary mode.

- Argumentative-orientation condition: obligation to reply in the expected way, i.e., to confirm the content of the question or its argumentative orientation.

We posit that discontinuity exists as soon as the second element in the pair does not totally or partially satisfy the constraints imposed by the first element (Trognon \& Musiol, 1996; Musiol et al., 1998). In line with this definition, V51/V55b (I1/DA1-DA2) is the first element in the pair, Ii, and X56 (I2/DA1) is the second element in the pair, Ij. The discontinuity was generated here by the violation of three out of four conditions: thematic (the patient introduced a new topic), propositional content and argumentative orientation (the new topic in fact introduced a new discourse universe). The second element in the pair, $\mathrm{Ij}$, was an unexpected response to the first element, Ii, in the framework of the general theme of the conversational transaction introduced more globally by the "normal" interlocutor.

Among the different types of constraints described in discourse analysis, withinintervention chaining constraints pertain to the subject's coordination of his/her own discourse; they are discourse planning constraints. Planning operates at various levels, depending on the complexity of the discourse. The following example exhibits a withinintervention discontinuity (non-decisive). By that token, it reveals a disorganized discursive production and thus, impaired discourse planning.

Example 2 (A is the schizophrenic interlocutor) 4

A25: $\quad$ my mother Sophie

M26: yes

A27: $\quad$ my adopted mother uh $(\rightarrow)$

M28: she's not your adopted mother

3 The utterance act performed in X56, "I was born in S" is the constituent which, given the argumentative structure of I2, should satisfy the discursive constraints imposed by I1's directing component

${ }^{4}$ Sequence taken from a corpus of Bernard Pachoud (1996). 
A29: I treat her as an adopted mother, don't know why

M30: $\quad$ who who might your mother be $(\uparrow)$

A31: when I say adopted mother it was to reassure myself it's to $(\rightarrow)$ uh how can I say this $(\rightarrow)$ uh I'm $(\rightarrow)$ uh I'm happy [to see her / to have her] ${ }^{5}$ (laughs) I'm taking my glasses off I can't see clearly Mister P (name) +2+

This is a within-intervention discontinuity occurring during a monologue. The patient unexpectedly changes focus in A31, "uh I'm, uh, I'm happy [to see her/ to have her]" since he is embarrassed to reply to the request for further information regarding his doubts about his ancestry. Failing to justify his self-doubts, it seems as if he switches to something else. The thing that makes this switch into a discontinuity, i.e., the thing that goes against the listener's expectations, and distinguishes this mode of chaining from a simple avoidance strategy, is that the speaker gives no sign of changing subjects and does not mark his abandonment of his initial plan (Musiol \& Pachoud, 1999). Notice also that a syntacticsemantic ambiguity is conveyed by this speech act. Due to the lexical ambiguity of the segment "to see her/ to have her", it has at least two potential meanings, endowed with distinct inferential potentials -- the logical form ${ }^{6}$ can be instantiated by proposition $\mathrm{p} 1$, whose syntactic-semantic structure is "I'm happy to see her", or by proposition p2, whose syntactic-semantic structure is "I' $m$ happy to have her".

From the pragmatic standpoint, the patient is insufficiently cooperative (Grice, 1975), which shows up in his discourse as a violation of the coordination constraints: the patient changes focus not only without negotiating the change, but also without even marking it (even though a conjunction like "in any case" would have sufficed). This is why we can speak of discontinuity here, a discontinuity that can be interpreted as a violation of the thematicchaining constraint or the topic-negotiation constraint. Within the intervention structure, the thematic constraint requires "the next constituent to be about a thematic element accessible from the first constituent, or, in the 'strong version' of that constraint, to be about the object of discourse (the intended theme of that constituent)" (Auchlin, 1988).

Note that this discontinuity is followed almost immediately by another one, as if, after violating a coordination constraint, the patient were unable to "get his discourse plan back" and started stringing utterances together in a random fashion, or rather in a one-by-one fashion based on mere contiguity, i.e., by hooking up to one of the last words pronounced, here the word "see", as in the following sequence: "when I say adopted mother it was to reassure myself / break $1 \Rightarrow$ / I'm happy [to see her / to have her] / break $2 \Rightarrow$ / I'm taking my glasses off I can't see clearly".

Such discontinuities in a speaker's discourse, which can be interpreted as violations of the constraints of coordination, in fact correspond to discontinuities in the speaker's intention (which the "normal" listener was trying to grasp) discontinuities that accentuate the meaning's indeterminate nature and prevent its confirmation later on in the discourse.

\footnotetext{
${ }^{5}$ The patient said /lavwaR/, which has two possible meanings in French: to see her ("la voir") and to have her ("l'avoir")

${ }^{6}$ For Pollock (1997), "The logical form is an interface between the mental language and the other cognitive systems involved in the intention and the reference [...] Representations of the logical form contain only terms that are semantically interpretable in a universal vocabulary (quantified referential expressions, variables, chains, etc.)."
} 
At the very first level of theoretical interpretation, violation of the coordination constraints underlying the different types of non-decisive discursive discontinuity can be explained in terms of deficits. In the light of the assumptions of cognitive neuropsychology (Frith, 1992), these difficulties could be the expression of an impaired ability to represent actions in the form of "intentions"; such a deficit would have an impact on the ability to plan one's actions. In this view, discourse planning during an interlocution can only be distinguished from more atomic action-planning processes by the greater complexity of the planning strategies it requires. Indeed, planning one's discourse during a conversation is an extremely subtle task that requires not only planning the discourse itself (the linearity of the language imposes a sequential rendition of what one is trying to say), but also, with every new speaking turn, adapting it to what was just said; this means improvising one's next remark to fit the situation, which itself must be reassessed in an ongoing manner (Musiol \& Pachoud, 1999; Pachoud, 1996).

\subsubsection{Properties of decisive discontinuity}

In our model's current state of development, there are two types of decisive discontinuity. We call the first type "conversational gear shifting" (Trognon, 1992; Trognon \& Musiol, 1996). Discontinuities of this type disrupt the turn-taking process while sequentially satisfying the chaining constraints of two directing interventions. They are characterized by a surreptitious change in the course of action by the speaker (here, the schizophrenic patient), despite the fact that he/she was the initiator. Consequently, the referential context changes without any indication of that change on the part of the speaker.

This sequence is made up of a ternary exchange, E, so it contains three directing interventions, I1, I2, and I3. The first intervention (the initiating one), I1, is supported by speaking turn G42 and is qualified as complex insofar as it is comprised of several speech acts. The directing act of this intervention is the act "I was supposed to have a wedding with 3000 guests". The reactive-initiative intervention (I2) is also complex; it is comprised of three speaking turns (A43-A44). The directing act of this intervention, labelled DA2, is supported by the speech act proffered in A44b "and a marriage to whom ( $\uparrow)$ " and two subordinate exchanges (SE), each of which consists of two interventions, A43-G43a, and G43b-A44a. Finally, the third intervention (called the reactive intervention), I3 -- also complex because it contains several speech acts (G44a-G44e) -- is supported in particular by the utterance act performed in G44a "whoever'll want me", which subordinates the rest of the speech acts in that intervention.

Example 3 ( $\mathrm{G}$ is a female schizophrenic interlocutor)

G42: $\quad(. .$.$) so you you has no idea (\rightarrow)$ it's a big deal you know $(\rightarrow)$ having a daughter and being $(\rightarrow)$ being (stammers) a virgin then being deflowered and all that $(\rightarrow$ ) abandoned you know $\left(\rightarrow\right.$ I'm like you $(\rightarrow \text { I'm [no longer her / a virgin] }]^{7}$ now $(\rightarrow)$ I'm a virgin $(\rightarrow)$ I've got a little girl $(\rightarrow$ ) I have $(\rightarrow$ ) like you $(\rightarrow)$ but like you $(\rightarrow)$ but I should have $(\rightarrow$ ) never have $(\rightarrow)$ gone out with $\left(\rightarrow\right.$ ) I still would've been a virgin $(\rightarrow)$ I would've be ${ }^{8}$ married in white $(\rightarrow)$ in a

\footnotetext{
7 Due to a language impairment typical of schizophrenics, it was not clear whether the patient said "pucelle" / pysel/, a French slang word for "virgin", or "plus celle" / plysel/, meaning "I'm no longer her" ${ }^{8}$ Note that the patient's exact words were "je m'aurais marié" (use of the auxiliary "avoir" instead of "être"). This grammatical error is commonly made by native French speakers with poor mastery of the language
} 
big ceremony $(\rightarrow)$ I was supposed to have a wedding with 3000 guests $(\rightarrow)$ how does that sound to you $(\uparrow)$

A43: $\quad 3000(\uparrow)$

G43: $\quad 3000$ guests $(\rightarrow)$ so you can see that I've got enough

A44: $\quad$ my God I see $(\rightarrow)$ and a marriage to whom $(\uparrow)$

G44: $\quad$ whoever'll want me $(\rightarrow)$ if it's Luke it's Luke $(\rightarrow)$ if it's not Luke $(\rightarrow)$ it'll be another $(\rightarrow)$ another American $(\rightarrow)$ hey I'm not worrying about it anymore $(. .$.

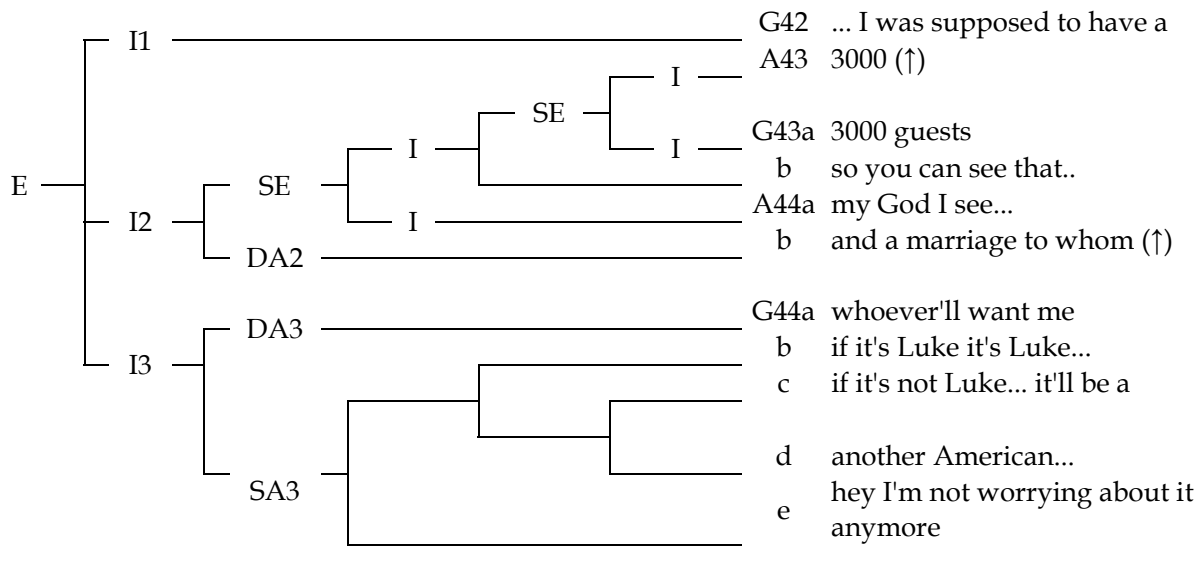

Legend. E: exchange. SE: subordinate exchange. I: intervention. DA: directing act. SA: subordinate act. G: interlocutor G. A: interlocutor A.

Fig. 2. Commented hierarchical diagram of Example 3.

In this sequence, then, it is schizophrenic patient $G$ who, in G42, initiates a narration (in which her interlocutor agrees to participate) of the wedding she was supposed to have (first intervention, labelled the initiating intervention). The directing constituent "and a marriage to whom ( $\uparrow$ )" (second intervention: A44b) also contributes to this narration. The reference universe of this question corresponds to an "imaginary" wedding related by G. This second intervention can also be interpreted as a question about G's future marriage plans, and this is the interpretation that $G$ links into, via a third directing intervention in G44a. But her remarks are unexpected, to say the least. We will say here that $G$ "shifts gears" during this third phase of the interaction. Now, although a conversational discontinuity like failing to answer a question or not replying to the point being made can be interpreted as a refusal to communicate, a conversational shift of gears cannot be interpreted as such. Indeed, on the third speaking turn, the initial speaker (here the schizophrenic patient) satisfies the betweenintervention constraints of the interlocutionary pair at the very same time as she "shifts gears".

Conversational sequences in which the patient shifted gears were in fact quite typical here. They consisted of three interventions that were not necessarily consecutive. The first intervention, made by the patient, initiated a course of action whose realization required the interlocutors to perform a series of subactions, usually involving several speaking turns. The second intervention, by way of which the interlocutor pursued the conversation, had the 
particularity of being interpretable as an action which both accomplished part of the course of action initiated by the preceding intervention, and initiated a new course of action. The schizophrenic patient linked into this via a third intervention, which in most cases, satisfied the between-intervention constraints (also called "interactional" constraints); however, in cases of gear shifting, the patient pursued the new course of action (Trognon \& Musiol, 1996).

Conversational gear shifting can in fact be formally described in the following manner. Let I1, I2, and I3 be three interventions that follow each other in a conversation, although not necessarily consecutively. Of the three component pairs in this sequence, (I1, I2), (I1, I3), (I2, I3), two exhibit continuity and one exhibits discontinuity. The continuous pairs are (I1, I2) and (I2, I3). Intuitively, these pairs exhibit continuity because their components -- for example, I1 and I2 for the pair (I1, I2) -- belong to the same discourse universe. However, the thematic universes of (I1, I2) and (I2, I3) are disjoint, albeit non-contradictory. Furthermore, abstractly speaking, the meaning of I2 is the union of the meanings at play in (I1, I2) and (I2, I3). It all seems as if this three-intervention sequence formed two parallel thematic series, with I2 serving to switch from one series to the other. This is precisely what makes the pair (I1, I3) discontinuous. In switching from the first series to the second series, I2 loses some of its properties. Indeed, two sets of properties characterize a conversational component. The first includes the semantic-pragmatic properties attached to the components' literal meaning, so the illocutionary force belongs to this set. The second includes the properties that describe how the component fits into the organization of the conversation, such as whether the component is directing or subordinate (Trognon \& Musiol, 1996). So, the

Example 4 (J is the schizophrenic interlocutor)

J142: Well I where I really suffered it's when I had my concussion

V143: $\quad$ It was due to an accident $(\uparrow)$

J144: $\quad$ Yes well somebody practically knocked me over $(\downarrow)$ it's really a $(\rightarrow)$ it's a $(\rightarrow)$ who threw me $(\rightarrow)$ who was in front and me behind and who $\rightarrow$ but well I don't care because $(\rightarrow)$ well I was loaded I actually had 5 liters of wine of $(\rightarrow)$ of Pineau 5 liters of beer plus 1 or 2 (inaudible)

V145: That you had drunk $(\uparrow)$

J146: We were going to the farm in S (place) $(\downarrow)$ an abandoned farm $(\downarrow)$ that Henry lives in $(\rightarrow)$ that belongs to Henry (inaudible) uh $(\rightarrow)$ a house that what was it what was it $(\rightarrow)$ that somebody got $(\downarrow)+$ me I liked I like Frank $(\downarrow)$ Frank L (name) $(\downarrow)$ he saved me $(\rightarrow)$ with his brother (inaudible)

V147: He saved you how $(\uparrow)$

J148: $\quad$ What $(\uparrow)$ V149: How did he save you $(\uparrow)$

J150: $\quad$ Ah but uh $(\rightarrow)$ who uh $(\rightarrow)$ well he saved me uh because I was with him because he $(\rightarrow)$ was DRINKing I mean $(\downarrow)$ he wanted to $(\rightarrow)$ hit me + and besides his brother kidnapped me $(\downarrow)+2+$ well what helps me here is a good guy it's Damien $(\downarrow)$ um luckily he did that to me because $(\rightarrow)$ he was doing like this he was making himself disappear $+1+$ and I can do it myself disappear $+1+$

V151: So you could disappear and reappear $(\uparrow)$

J152: $\quad$ Yes $(\downarrow)$

${ }^{9}$ Pineau is a sweet wine that is slightly stronger than a standard dinner wine. 


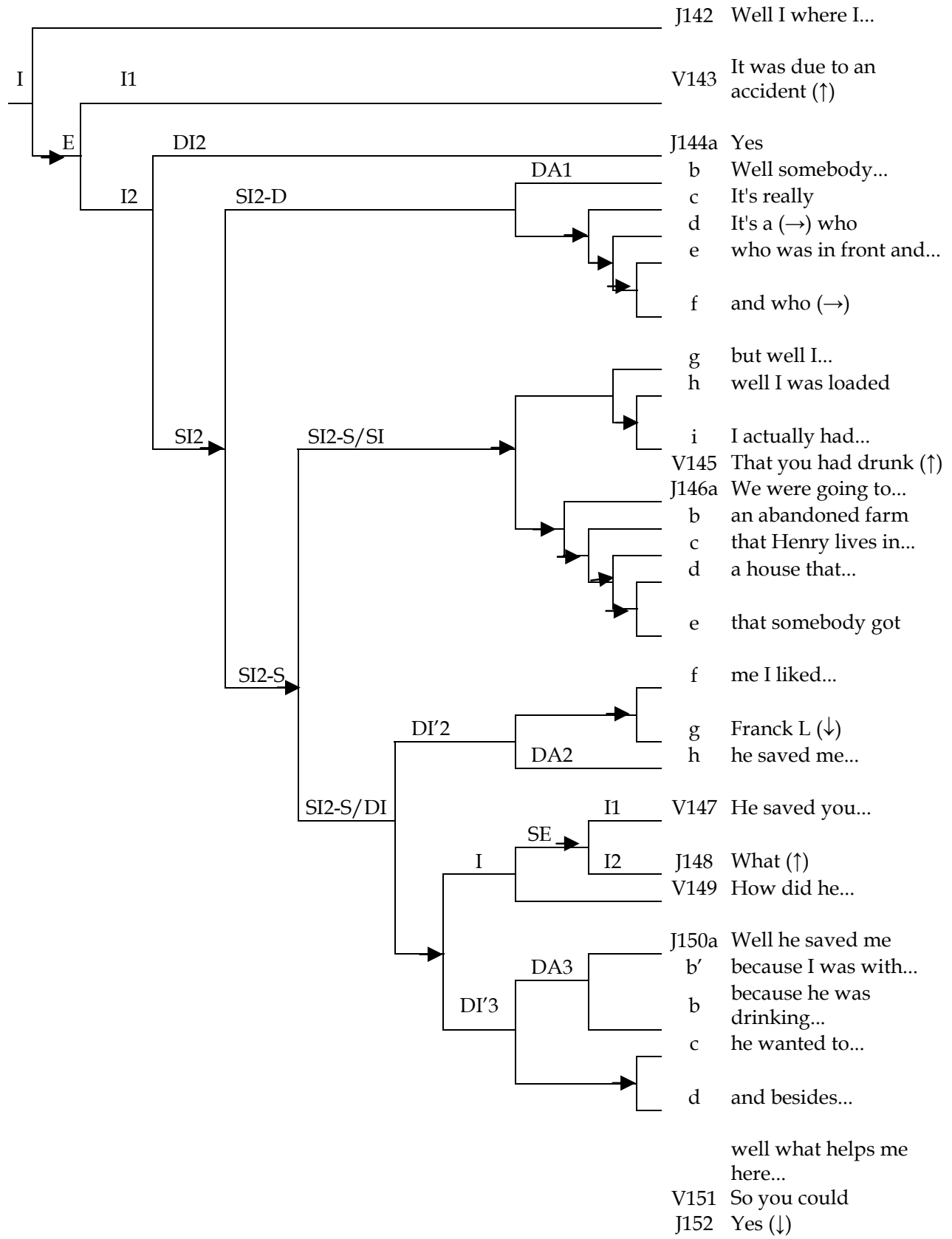

Legend. E: exchange. SE: subordinate exchange. I: intervention. DI: directing intervention. SI: subordinate intervention. DA: directing act. V: interlocutor V. J: interlocutor J.

Fig. 3. Commented hierarchical diagram of Example 4. 
meaning of I2 in the second series now only retains the semantic-pragmatic properties of this element, as if $\mathrm{I} 2$ could somehow be withdrawn from the conversational structure to which it belongs in order to be treated abstractly and literally.

Our model involves a second type of decisive discontinuity qualified as a "defective conversational initiative". Granted, this type of within-intervention discontinuity consists of chaining that sequentially satisfy the interactional constraints governing the organization of the exchange-level subcomponents of the complex transaction unit. Yet it consists specifically of discontinuities that are inherent in the hierarchical and functional relations governing the sequentialization of speech acts of different levels (in the sense that an act can impose interactive constraints on the constituent that follows it or even precedes it, while still being dependent upon it at the hierarchical and functional level), which subsume or support the argumentation of the interlocutor who initiated the conversational transaction, e.g., the schizophrenic patient.

This hierarchical and functional diagram brings out a complex intervention structure. This intervention will be called self-initiated -- in the present case, initiated by the schizophrenic patient. It can be subdivided into two parts. The first has a single constituent, J142, which is the transaction's directing constituent at the intervention level. The second is a complex exchange-level constituent that progresses through eight other speaking turns in the transaction; it is the subordinate component of the exchange-level transaction that extends from V143 to J150.

The two directing constituents of this exchange are V143, a simple intervention (I1) performed by the "normal" interlocutor, and a complex intervention (I2) which runs from J144 to J150 and is itself made up of two complex parts, DI2 conveyed by speech act J144a -which is an act of confirmation and is the directing element of this intervention -- and SI2, a subordinate intervention that progresses across J144b and J150d. The second part of this intervention will also be called complex. Its dynamic progression from J144b to J150d unfolds at the first analysis level by way of two subcomponents, themselves endowed with a complex structure: SI2-D (J144b to J144f) and SI2-S (J144g to J150d). The first-level directing act of this constituent is accomplished in J144b, i.e., "well somebody practically knocked me over". It is only as the discursive segments of this complex intervention (SI2) progress and are articulated each in turn that we gradually uncover the main characteristics of the defectiveness of the patient's conversational initiative. Statement $144 \mathrm{~b}$ will be called the "directing act" (DA1) of the first-level directing constituent of this complex interventionlevel component. Likewise, $144 \mathrm{~b}$ is the directing constituent of directing intervention SI2-D, which itself forms the directing part of this complex component (SI2). The substructure SI2D thus dominates SI2-S, itself highly complex, and as such, dominates the key act of this substructure, here again called "directing". We are speaking of the act accomplished in J146h, i.e., "he saved me with his brother". This subordinate part, SI2-S, runs across J144g and J150d. In turn, SI2-S includes a subordinate part going from J144g to J146e (SI2-S/SI) and a directing part going from J146f to J150d (SI2-S/DI). At the hierarchical and functional level, SI2-S/DI is comprised of two complex intervention-level constituents in a subordination relation: DI'2, which extends from J146f to J146h with J146h as its directing act (DA2), and DI'3, which spans from J150a to J150d. The directing act of this intervention is complex; it is composed of two segments, 150a and 150b, articulated around the connective "because", which has a causal function. Moreover, directing act DA3 is associated interactively to subordinate act J150b' (preparatory function), which is incorporated into the directing act's 
structure and into subordinate acts J150c and J150d, both of which fulfill a justifying function. Insofar as we are describing the structure of a complex intervention-level component, namely SI2-S-DI, we will acknowledge -- while drawing from Roulet's (Roulet et al., 1985) model -- that DA2 imposes constraints of the interactive type on DA3. Likewise, insofar as component SI2-S-DI is itself an integral part of complex intervention SI2, of which SI2-D is the directing element, we will acknowledge that DA1 imposes interactive constraints on both DA2 and DA3. Indeed, DA1 is the directing constituent of complex intervention SI2-D, which subordinates SI2-S globally, i.e., dominates both DA2 and DA3.

We can see here that, at the dialogical level, the discontinuity is generated by a multilayered process, in the sense that DA3, namely utterance J150a-b "he saved me because he was DRINKing I mean", satisfies neither the argumentative-relation constraint imposed by DA2, that is, utterance J146h "he saved me with his brother", nor the argumentative-relation constraint imposed more distally by DA1, that is, utterance J144b "well somebody practically knocked me over". Clearly, the utterance act performed in DA3 "he saved me because he was DRINKing I mean" (just like the acts that contribute more globally to the coherence of the subcomponent dominated by DA2, such as "he saved me with his brother") can in no way be seen as a discursive constituent of the rhetorical "argument-conclusion" relations imposed on it by discursive constituent DA2, which plays the role of argument here. Moreover, we can also see that this same constituent, DA2, does not satisfy the constraints imposed on it by hierarchical constituent DA1, which dominates it hierarchically. Hence, "he saved me with his brother" (DA2) does not satisfy the interactive constraints -- which once again are argumentative-relation constraints -- theoretically imposed on it by DA1, that is, "well somebody practically knocked me over". We will agree in addition, based on the hierarchical analysis of this sequence, that DA3 is no better at satisfying the interactive constraints imposed on it by DA1. The rest of the sequence conveys other artefacts and incongruities, but we will stop our commentary at this point since the elements of analysis presented so far suffice for our demonstration.

More generally, J150 is made up of another series of speech acts that introduce a new topic to which the interlocutor will contribute. We are thus in the presence of two distinct conversational transactions: the first (analyzed above) stops precisely at the end of J150d; the second begins with the dialogue-resumption segment "well what helps me here".

At the hierarchical and functional level, within-intervention constraints pertain to the proper formulation of interventions. Roulet's (Roulet et al., 1985) book defines them as follows:

- Thematic condition: obligation in the intervention to pursue the object of discourse presented in the intervention's first constituent, whether implicitly or explicitly.

- Argumentative-relation condition: obligation to pursue the intervention using a constituent capable of entering into an argumentative relation (be an argument or conclusion) with the intervention's first constituent.

- Argumentative-orientation condition: obligation, within the intervention, to continue with a constituent that does not contradict the argumentative orientation of the intervention's first constituent.

A complex intervention exhibiting discontinuity is theoretically composed of various actlevel components, exchange-level components, and intervention-level components. These various components may be nested (e.g., an intervention can contain an exchange as a subpart of itself) and be combined into more complex units (interrelated hierarchically and functionally). We will call these units the subcomponents of the complex intervention. Being 
deemed relevant to analyzing this type of conversational transaction, these units are related to each other via domination relations at the rhetorical level; a given subcomponent of the complex intervention always either directs or is subordinate to one or more associated units. In addition, each potential subcomponent has its own internal coherence (if it consists of more than one speech act) and is functionally dependent on the subcomponents that surround it both upstream and downstream, but here again, in a more or less distal way. The functions operating inside a subcomponent are necessarily of the interactional and interactive type (they must satisfy both between- and within-intervention constraints), but the functions that associate the subcomponents to each other are solely of the interactive type.

Sequences exhibiting conversational initiative defectiveness contain at least three directing acts, e1, e2, e3, in a hierarchical and functional relation of domination derived from simple or complex intervention-level constituents. The domination relation defines three pairs [e1, e2], [e2, e3], and [e1, e3] whose dialogical rationality is such that the first element of the pair, e (the source element) puts the second element, $\mathrm{e}^{\prime}$ (the target element) in a strategic interactive relationship with itself that is based on three conditions: the thematic condition, whereby e' must implicitly or explicitly continue with the object of discourse presented in e, the argumentative-relation condition, whereby $\mathrm{e}^{\prime}$ must be an argument or a conclusion of e, and the argumentative-orientation condition, whereby e' must not contradict e in any way. Conversational initiative defectiveness is considered to exist if e3 does not satisfy one or more of the three interactive conditions imposed on it by e2 in the pair [e2, e3] or by e1 in the pair [e1, e3], or if e3 does not satisfy one of more of the three interactive conditions imposed on it by e2 in the pair [e2, e3] and e2 does not satisfy one or more of the three interactive conditions imposed on it by e1 in the pair [e1, e2].

\subsubsection{Heuristic aspect of the analysis method}

By analyzing numerous sequences from pathological verbal interactions, we were able to bring out several characteristics of the type of discontinuity called manifest or decisive (Musiol, 2002).

Although a patient's utterance discontinuity or discourse incongruity can be counteracted in a conversation by the interlocutor's verbal behavior, it is clear that conversational discontinuities of the within- or between-intervention type retain some degree of nondecisiveness. Only "conversational gear shifting" and sequences containing "conversational initiative defectiveness" can currently be seen as transactions where the patient's behavior might be "incoherent". Furthermore, the mere fact of detecting incoherence does not imply that there is a thought disorder, and therefore does not itself authorize an interpretation of this deficient interlocutionary behavior in terms of dysfunctional thought. What we do hypothesize, however, is that detecting decisive incoherence is an intermediate stage -- i.e., $a$ sufficient but non-necessary condition ${ }^{10}$ for any attempted interpretation in terms of psychopathology. We are also working on articulating the pragmatic-dialogical analysis of decisive sequences with the help of a formal semantic model, in view of "accessing" the properties and rationality of the semantic representations (Musiol \& Rebuschi, 2011) of

\footnotetext{
10 Under this hypothesis, the occurrence of a discontinuity of the decisive type is the sign of a dysfunction in the cognitive system, affecting, for example, cognitive-linguistic processes, cognitiveinferential processes, or their interface. The absence of this type of discontinuity in a corpus is not equivalent to the absence of pathology (the model may simply be insensitive to it).
} 
subjects with a psychiatric disorder, i.e., their intentional, interpretive, or inferential thought processes.

Through the pragmatic-dialogical formalization of the sequences analyzed above (conversational gear shifting and conversational initiative defectiveness), we were able to paint a more precise picture of the form and basic properties of decisive discontinuity. This kind of discontinuity is not sustained by the simple proposition, the speech act, or even the exchange, but by conversational transactions whose structure is based on rhetorical and semantic relations between at least three discursive segments. The conversational transaction is the relevant unit, not the act, the utterance, or the two-orthree turn exchange.

Thus, the decisive nature of incoherence shows up at the transaction level in two types of structures:

- in an exchange, understood a priori as a balanced dialogue unit opposing a speaker (e.g., a patient) to his/her interlocutor (e.g., a therapist); the conversational transaction is structured on the basis of at least three symmetrical directing moves.

- in a complex intervention, understood as an asymmetrical dialogue unit where the argumentation of one of the interlocutors (e.g., the patient) overrides that of his/her addressee; the conversational transaction is analyzed on the basis of hierarchical and functional relations between at least three discursive segments detected in the main discourse -- the hierarchical and functional relations between these three or more constituents subsume and support the unfolding of the interlocutor's argumentation.

\section{Study}

The purpose of this study was to use a pragmatic-dialogical model to link any verbalbehavior discontinuities detected in a patient to that patient's clinical manifestations (or syndromes) as diagnosed on the basis of DSM-IV criteria. The merits of using this model are clear: it provides a more accurate description of the symptomatic manifestations of schizophrenia -- as they are expressed in verbal interaction in the form of syndromespecific discontinuities -- and thereby allows us to show how these discontinuities cooccur with the clinical manifestations generally described in disease classification systems. From this, we should be able to set forth some specific hypotheses about the potentially distinct properties of the underlying cognitive processes. The models that account for non-decisive discontinuity in verbal interaction are congruent with a potential dysfunction in psychophysiological or neurocognitive processes like the ones involved in planning, for example. The models that account for decisive discontinuity in verbal interaction are congruent with potential impairment of representational or metarepresentational cognitive processes (complex thought processes like intentional or inferential processes).

The characteristics of our empirical-investigation corpus (Table 1) also make it possible to control for the potential impact of antipsychotic medication on the expression of symptoms as they show up in verbal interaction. As stated at the beginning of this article, psychometric scales have traditionally been used to measure the effectiveness of neuroleptic treatment, and research in this area has mainly focused on the ability of these scales to assess the comparative effects of conventional (first generation) and atypical (second generation) neuroleptics on schizophrenic symptoms. While few studies contest the effectiveness of neuroleptics on schizophrenic symptoms (especially positive ones), the question of their 
mechanisms of action and their repercussions on cognition are still widely debated. Some studies have shown that the cognitive performance of schizophrenic patients improves more with atypical than with conventional neuroleptic medication (Goldberg \& Weinberger, 1995; Harvey et al., 2003; Meltzer \& McGurk, 1999), but their effectiveness is still being questioned.

\section{Method}

\subsection{Participants}

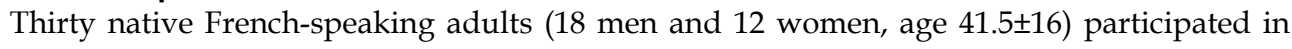
the study. Twenty-two of the participants (14 men and 8 women, age $45.0 \pm 15.4$ ) were assigned to the schizophrenic group (SCH) and eight (4 men and 4 women, age 32.1 \pm 14.3 ) were assigned to the control group (CTR). Two group of schizophrenic patients were formed on the basis of their TLC scores (Thought, Language and Communication Scale, Andreasen, 1979) by two experienced psychologists. Patients without thought disorder (non-thought-disorder patients (NTD), n=11) obtained a TLC score $<7$ (mean $3.5 \pm 1.7$ ), and patients with thought disorder (thought-disorder patients (TD), n=11) obtained a TLC score $>$ or $=7(13.6 \pm 3.0)$. The biographical characteristics of the sample are given in Table 1 .

Among the 22 schizophrenic participants included fulfilling the Diagnostic and Statistical Manual of Mental Disorders IV (DSM-IV, American Psychiatric Association, 1994), 15 were being treated with antipsychotic drugs ((N)TD-A: mean dose equivalent to $281 \pm 118 \mathrm{mg} /$ day of chlorpromazine) and 7 were taking no medication ((N)TD-N). The clinical types of the schizophrenics were as follows: there were 14 paranoid schizophrenics ( 5 of whom were taking antipsychotic drugs) and 8 disorganized schizophrenics ( 2 of whom were not taking any antipsychotic medication). The antipsychotic medication taken by the 15 schizophrenic patients was atypical (second generation), conventional (first generation), or a combination of the two. The patients had no neurological disorders and had not suffered from alcoholic intoxication or used any toxic substances for at least three months before the study. The diagnosis of schizophrenia was made by experienced psychiatrists who were not taking part in the study.

The schizophrenic patients were encountered in two different clinical institutions. Seven of them were in the psychiatric emergency ward (Temporary Psychiatric Hospitalization Unit in Troyes, France). They were apparently experiencing their first encounter with the psychiatric world and were not taking antipsychotic drugs. For these participants, no data indicating prior hospitalization in a psychiatric ward could be found. Given that a diagnosis of schizophrenia cannot be pronounced unless the signs of the disorder persist for at least six months (APA, 1994), we had to verify the diagnosis six months later. The diagnosis was indeed confirmed in all cases, although once again, the data was collected at the time of hospitalization. The other 15 patients had been under treatment in a psychiatric ward for at least three years (at the Specialized Hospital of La Rochelle, France). They benefited from daily antipsychotic treatment. Among these 15 patients, 5 were encountered in the specialized hospital where they were inpatients; the other 10, who were hospitalized only intermittently.

Like the schizophrenic patients, the control participants had no neurological disorders and had not suffered from alcoholic intoxication or used toxic substances for at least three 
months before the study. They had no diagnosed psychiatric disorders and were not taking any psychotropic medication. The controls were encountered in public places.

\begin{tabular}{|c|c|c|c|c|}
\hline & \multicolumn{2}{|c|}{$\begin{array}{c}\mathrm{SCH} \\
(\mathrm{n}=22)\end{array}$} & \multirow[b]{2}{*}{$\begin{array}{c}\mathrm{CTR}(\mathrm{n}=8) \\
\mathrm{M} \pm \mathrm{SD}\end{array}$} & \multirow[b]{2}{*}{ Total } \\
\hline & $\begin{array}{c}\text { NTD }(\mathrm{n}=11) \\
(\mathrm{NTD}-\mathrm{A} / \mathrm{NTD}-\mathrm{N}) \\
\mathrm{M}+\mathrm{SD}\end{array}$ & $\begin{array}{c}\mathrm{TD}(\mathrm{n}=11) \\
(\mathrm{TD}-\mathrm{A} / \mathrm{TD}-\mathrm{N}) \\
\mathrm{M}+\mathrm{SD}\end{array}$ & & \\
\hline Sex $(M-F)$ & $(\overline{7-4)}$ & $\overline{(7-4)}$ & $(4-4)$ & - \\
\hline $\begin{array}{l}\text { Clinical subtypes } \\
\text { Paranoid } \\
\text { schizophrenics - } \\
\text { Disorganized } \\
\text { schizophrenics }\end{array}$ & $(7-4)$ & $(7-4)$ & - & \\
\hline Age in years & $40,2 \pm 15,3$ & $49,7 \pm 14,7$ & $32.1 \pm 14.3$ & - \\
\hline $\begin{array}{l}\text { Education } \\
\text { (in no. of years of } \\
\text { schooling from first } \\
\text { grade on) }\end{array}$ & $9,6 \pm 1,7$ & $7,4 \pm 3,2$ & $9.1 \pm 1.4$ & - \\
\hline $\begin{array}{l}\text { Chlorpromazine } \\
\text { equivalent in mg } \\
\text { per day }\end{array}$ & $\begin{array}{c}200 \pm 144 \\
(276 \pm 75 / 0)\end{array}$ & $\begin{array}{c}182 \pm 183 \\
(286 \pm 146 / 0)\end{array}$ & - & - \\
\hline Time since onset & $5,8 \pm 4,8$ & $11,2+13,5$ & - & - \\
\hline TLC score & $\begin{array}{c}3,5 \pm 1,7 \\
(3,2 \pm 1,9 / 4,3 \pm \\
0,6)\end{array}$ & $\begin{array}{c}13,6 \pm 3 \\
(14,1 \pm 3,7 / 12,8 \pm \\
1,3) \\
\end{array}$ & - & - \\
\hline $\begin{array}{l}\text { Number of } \\
\text { interviews }\end{array}$ & $11(8 / 3)$ & $11(7 / 4)$ & 8 & 30 \\
\hline $\begin{array}{l}\text { Number of } \\
\text { conversational } \\
\text { transactions }\end{array}$ & 124 (105 / 19) & $234(149$ / 85) & 45 & 403 \\
\hline
\end{tabular}

Legend. NTD: schizophrenics without thought disorder. TD: schizophrenics with thought disorder. (N)TD-N: schizophrenics with no treatment. (N)TD-A: schizophrenics under antipsychotic treatment. CTR: participants with no diagnosed psychiatric disorders. n: number of patients. M: mean. SD: standard deviation.

Table 1. Characteristics of the Investigation Corpus

Concerning the sociodemographic variables, pairwise comparisons (Student's $t$-test for independent samples) of our groups (NTD vs. TD, NTD vs. CTR, TD vs. CTR) did not yield any significant differences in education $(t[1,20]=1.694, p=.114 ; t[1,17]=0.654, p=.524$; $t[1,17]=-1.368, \mathrm{p}=.194$ ) or sex (corrected Chi2: $\mathrm{p}=.803$ ). There was no significant differences for age $(t[1,20]=-1.492, p=.151 ; t[1,17]=1.164, p=0.260)$ excepted between group TD and the control group $(t[1,17]=2.604, \mathrm{p}=.019)$. A comparison of the two schizophrenic groups (NTD and TD) on time-since-onset indicated no significant difference $(t[1,20]=-1.244, p=.236)$. Regarding the neuroleptic treatment of these two groups (mean chlorpromazine-equivalent dose in $\mathrm{mg} /$ day), no significant difference was found 
$(t[1,20]=.272, \mathrm{p}=.789)$. Given that both patient groups contained neuroleptic-treated and untreated individuals, we also compared the treated schizophrenics with no formal thought disorders (NTD-A) and the treated schizophrenics with formal thought disorders (TD-A): no significant difference was found here either $(t[1,13]=-0.154, p=.881)$. The medication factor should therefore not interfere with the results. The TLC scores of the two schizophrenic groups (NTD and TD) were highly significantly different $(t[1,20]=-9.691, p<.001)$. There was a highly significant difference too between group NTD and the control group $(t[1,17]=6.938, \mathrm{p}<.001)$ and between group TD and the control group $(t[1,17]=15.030$, $\mathrm{p}<.001)$.

\subsection{Procedure}

The study was based on a pragmatic and dialogical analysis of verbal transactions taken from a corpus composed of 30 interviews. In all cases, the interviewer was a research psychologist and the interviewee was either a schizophrenic patient or an individual with no psychiatric disorders. All of the interviewees agreed to have the conversation tape recorded so that we could compile our corpus. They were told why they were being recorded, and we did not conceal the fact that they were participating in a study. The instructions were simply to talk to the interviewer. If the interviewee said he/she was having trouble expressing him/herself at the beginning, the interviewer started with a relatively general topic of conversation (everyday activities and/or concerns).

The breakdown of the entire interview corpus gave us 403 conversational sequences (or transactions). Table 1 gives additional information about the interviews.

\section{Results}

\subsection{Classification of conversational sequences, by type of Interlocutor}

Our first step was to label the sequences as to whether they contained or did not contain a discontinuity, for each group of interlocutors. Again, the interlocutors were schizophrenics without thought disorder (NTD) or with thought disorder (TD), or individuals with no diagnosed psychiatric disorders (CTR).

Comparisons of the sequences with and without a discontinuity (whether decisive or nondecisive) across participant groups showed that the schizophrenics' conversational sequences $(\mathrm{SCH})$ contained more discontinuities than the "normal" participants' sequences. These two groups were significantly different $(\mathrm{Chi} 2=21.175, \mathrm{p}<.001)$. There were also more discontinuous sequences in the Thought Disorder schizophrenic subcorpus than in the control-participant subcorpus (Chi2 $=35.300, \mathrm{p}<.001)$ and more discontinuous sequences in the Thought Disorder schizophrenic subcorpus than Non-Thought-Disorder schizophrenic subcorpus (Chi2 $=54.726, \mathrm{p}<.001)$. These results thus suggest that the models we devised to account for discourse discontinuity are good at differentiating between "pathological conversations" and "normal conversations" in terms of coherence. This is hold true for comparing the two groups of schizophrenics defined on the basis of presence or absence thought disorder. We note a marginally significant between Non-Thought-Disorder group and the control group (Chi2 $=2,966, \mathrm{p}=.085$ ).

Now, when the interlocutors were schizophrenics of the paranoid (SCH-P) or disorganized type (SCH-D), or individuals with no diagnosed psychiatric disorders (CTR), comparisons of the sequences with and without a discontinuity (whether decisive or non-decisive) showed that the disorganized-schizophrenics' conversational sequences $(\mathrm{SCH})$ contained 
more discontinuities than in the control-participant subcorpus (Chi2 $=17.347, \mathrm{p}<.001$ ) and there were also discontinuous sequences in the paranoid-schizophrenic subcorpus than in the control subcorpus (Chi2 $=22.323, \mathrm{p}<.001$ ). These results thus suggest that the models we devised to account for discourse discontinuity are good at differentiating between "pathological conversations" and "normal conversations" in terms of coherence. This does not seem to hold true, however, for comparing the two groups of schizophrenics defined on the basis of clinical type. The sequences in the paranoidschizophrenic subcorpus did not have more discontinuities than those in the disorganized-schizophrenic subcorpus. These two subgroups did not differ significantly (Chi2 $=0.991, p=.319)$. Thus, irrespective of the medication variable and the type of discontinuity at play, the model failed to detect the specificities of each clinical type of schizophrenia. Our next step, then, will be to look at other variables in order to determine the specificities of each schizophrenic subtype.

Our next step, then, will be to look at other variables in order to determine the specificities of each type of discontinuity.

\begin{tabular}{|l|c|c|c|c|c|c|c|}
\hline & & & & \multicolumn{4}{|c|}{ p-value } \\
\cline { 5 - 8 } & NTD & TD & CTR & $\begin{array}{c}\text { SCH } \\
\text { vs } \\
\text { CTR }\end{array}$ & $\begin{array}{c}\text { NTD } \\
\text { vs } \\
\text { CTR }\end{array}$ & $\begin{array}{c}\text { TD } \\
\text { vs } \\
\text { CTR }\end{array}$ & $\begin{array}{c}\text { NTD } \\
\text { vs } \\
\text { TD }\end{array}$ \\
\hline $\begin{array}{l}\text { Sequences with } \\
\text { discontinuity }\end{array}$ & $\begin{array}{c}13 \\
(11 \%)\end{array}$ & $\begin{array}{c}117 \\
(50 \%)\end{array}$ & $1(2 \%)$ & $<.001$ & $\mathrm{p}=.085$ & $<.001$ & $<.001$ \\
\hline $\begin{array}{l}\text { Sequences } \\
\text { without } \\
\text { discontinuity }\end{array}$ & $\begin{array}{c}111 \\
(89 \%)\end{array}$ & $\begin{array}{c}117 \\
(50 \%)\end{array}$ & $\begin{array}{c}44 \\
(98 \%)\end{array}$ & & & & \\
\hline Total & 124 & 234 & 45 & & & & \\
\hline
\end{tabular}

Legend. SCH: schizophrenics. NTD: schizophrenics without thought disorder. TD: schizophrenics with thought disorder. CTR: individuals with no diagnosed psychiatric disorder.

Table 2. Presence or Absence of Discontinuity, by Participant Group

\subsection{Conversational sequences with or without a non-decisive discontinuity, by group of interlocutors}

Now let us look at the number of sequences with or without the type of discontinuity we call "non-decisive", for each group of interlocutors. The distribution of these sequences across groups is shown in Table 3, which also gives the significance level in each case. Sequences containing a decisive discontinuity (nine in all) were not included in the table, so the comparison shown here is between non-decisive discontinuous sequences and sequences with no discontinuities.

These results are very similar to those presented above, in that non-decisive discontinuities were more frequent in the schizophrenic subcorpus. When we compare the sequences with a non-decisive discontinuity to ones with no discontinuity across participant groups, we can see that the schizophrenics' conversational sequences contained more such discontinuities than those of the "normal" individuals. These two groups differed significantly (Chi2 $=19.633, \mathrm{p}<.001$ ). We also found more non-decisive discontinuous sequences in the Thought Disorder schizophrenic subcorpus than in the control-participant subcorpus 
(Chi2 = 33. 827, $\mathrm{p}<.001$ ), and more non-decisive discontinuous sequences in the Thought Disorder schizophrenic subcorpus than Non-Thought-Disorder schizophrenic subcorpus (Chi2 $=59.607, \mathrm{p}<.001$ ). Comparing the sequences with or without a non-decisive discontinuity between Non-Thought-Disorder group and the control group, we can see that these two groups were not significantly different $(\mathrm{Chi} 2=1.601, \mathrm{p}=.206$ ): the Non-ThoughtDisorder schizophrenic sequences did not contain more non-decisive discontinuities than the control ones.

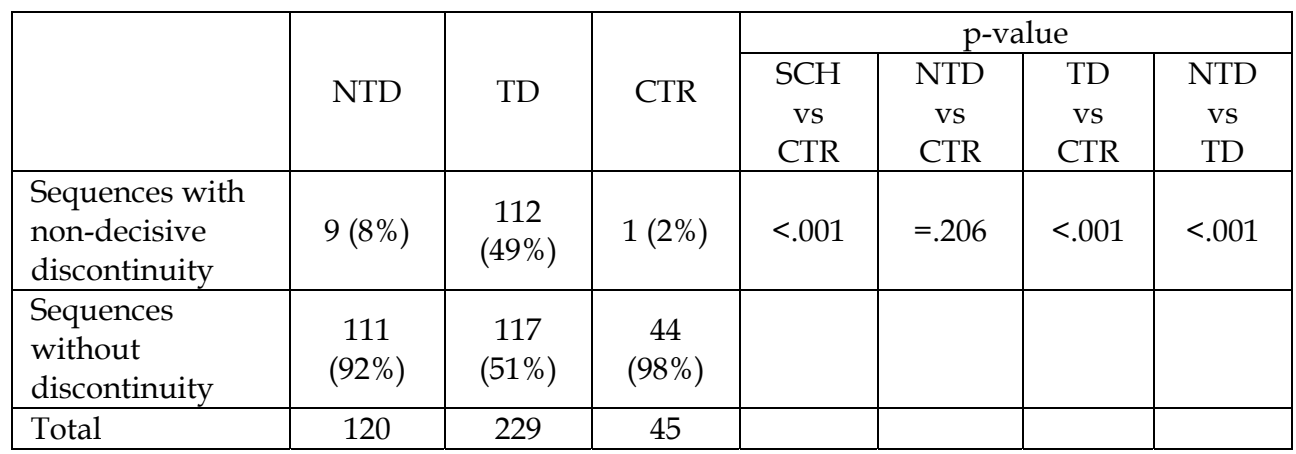

Legend. SCH: schizophrenics. NTD: schizophrenics without thought disorder. TD: schizophrenics with thought disorder. CTR: individuals with no diagnosed psychiatric disorder.

Table 3. Presence or Absence of Non-Decisive Discontinuity, by Participant Group

Now, when we compare the sequences with a non-decisive discontinuity to ones with no discontinuity across participant groups based on the clinical subtypes of schizophrenia (DSM-IV), we also found more non-decisive discontinuous sequences in the disorganizedschizophrenic subcorpus than in the control-participant subcorpus (Chi2 =17.347, $\mathrm{p}<.001$ ), and more non-decisive discontinuous sequences in the paranoid-schizophrenic subcorpus than in the control-participant subcorpus (Chi2 $=19.749, \mathrm{p}<.001)$. Comparing the sequences with or without a non-decisive discontinuity across clinical types of schizophrenia, we can see that these two patient groups were not significantly different (Chi2 $=0.208, p=.649)$ : the paranoid-schizophrenic sequences did not contain more non-decisive discontinuities than the disorganized-schizophrenic ones (see Table 4).

However, as suggested above and called for by our experimental design (see Table 1), additional information is needed regarding the potential interaction between our variables "clinical type of schizophrenia" and "medication" (Verhaegen \& Musiol, 2009). So we attempted to find out, firstly, whether SCH-P-N conversational sequences had fewer, as many, or more non-decisive discontinuities than other sequences, as compared to SCH-D-N conversational sequences, and secondly, whether SCH-P-A conversational sequences had fewer, as many, or more non-decisive discontinuities than other sequences, as compared to $\mathrm{SCH}-\mathrm{D}-\mathrm{A}$ conversational sequences (see Table 5).

For the schizophrenics who were not under treatment $(\mathrm{SCH}-\mathrm{N})$, there were more nondecisive discontinuities among the SCH-D than among the SCH-P (Chi2 = 22.015, p <.001). By contrast, for the patients taking antipsychotic medication (SCH-A), the SCH-P's nondecisive discontinuities outnumbered the SCH-D's (Chi2 = 13.141, $\mathrm{p}<.001)$. 


\begin{tabular}{|l|c|c|c|c|c|c|c|}
\hline & & & & \multicolumn{4}{|c|}{ p-value } \\
\cline { 5 - 8 } & SCH-P & SCH-D & CTR & $\begin{array}{c}\text { SCH } \\
\text { vs } \\
\text { CTR }\end{array}$ & $\begin{array}{c}\text { SCH-P } \\
\text { vs } \\
\text { CTR }\end{array}$ & $\begin{array}{c}\text { SCH-D } \\
\text { vs } \\
\text { CTR }\end{array}$ & $\begin{array}{c}\text { SCH-P } \\
\text { vs } \\
\text { SCH-D }\end{array}$ \\
\hline $\begin{array}{l}\text { Sequences with } \\
\text { non-decisive } \\
\text { discontinuity }\end{array}$ & $71(36 \%)$ & $50(33 \%)$ & $1(2 \%)$ & $<.001$ & $<.001$ & $<.001$ & 0.649 \\
\hline $\begin{array}{l}\text { Sequences without } \\
\text { discontinuity }\end{array}$ & $128(64 \%)$ & $100(67 \%)$ & $44(98 \%)$ & & & & \\
\hline Total & 199 & 150 & 45 & & & & \\
\hline
\end{tabular}

Legend. SCH-P: paranoid schizophrenics. SCH-D: disorganized schizophrenics. SCH: schizophrenics. CTR: individuals with no diagnosed psychiatric disorder.

Table 4. Presence or Absence of Non-Decisive Discontinuity, by Participant Group

\begin{tabular}{|l|l|c|c|}
\hline \multicolumn{2}{|c|}{} & SCH-P & SCH-D \\
\hline \multirow{3}{*}{ SCH-N } & $\begin{array}{l}\text { Sequences with non-decisive } \\
\text { discontinuity }\end{array}$ & $12(20 \%)$ & $28(67 \%)$ \\
\cline { 2 - 4 } & Sequences with no discontinuity & $47(80 \%)$ & $(33 \%)$ \\
\cline { 2 - 4 } & Total & 59 & 42 \\
\hline \multirow{3}{*}{ SCH-A } & $\begin{array}{l}\text { Sequences with non-decisive } \\
\text { discontinuity }\end{array}$ & $59(42 \%)$ & $22(20 \%)$ \\
\cline { 2 - 4 } & Sequences with no discontinuity & $81(58 \%)$ & $86(80 \%)$ \\
\cline { 2 - 4 } & Total & 140 & 108 \\
\hline
\end{tabular}

Legend. SCH-P: paranoid schizophrenics. SCH-D: disorganized schizophrenics. SCH-N: schizophrenics with no treatment. SCH-A: schizophrenics under treatment.

Table 5. Conversational Sequences With or Without a Non-Decisive Discontinuity, by Presence/Absence of Antipsychotic Medication and Clinical Type of Schizophrenia

\subsection{Conversational sequences with or without a decisive discontinuity, by group of interlocutors}

Lastly, we looked at the sequences with and without decisive discontinuities for each patient group. Nine sequences were compatible with our decisive-discontinuity model. The Nonthought-Disorder schizophrenic group contains four decisive discontinuity and the Thought-Disorder schizophrenic group contain five ones. The two groups were not significantly different. However, all nine sequences occurred in the paranoid-schizophrenic subcorpus. This subgroup differed significantly from both the disorganized-schizophrenic group (binomial test $p=.002$ ) and the "normal" group (binomial test $p=.002$ ). Among these nine paranoid schizophrenics, three were from the no-medication group (SCH-P-N) and six were from the antispsychotic-medication group (SCH-P-A). 


\section{Discussion}

These results indicate that the pragmatic and dialogical discontinuity models we developed (decisive and non-decisive models) turned out to be good at discriminating schizophrenic patients from individuals with no psychiatric disorders in terms of conversational coherence. In addition, they accounted for certain coherence-related specificities of the discursive and dialogical productions of patients with each of the subtypes of schizophrenia we studied (paranoid and disorganized). We were able to point out a strong correlation between the paranoid clinical type and a particular kind of "discontinuous" verbal behavior, namely, decisive discontinuity, both for paranoid schizophrenics with and without antipsychotic treatment.

Our decisive-discontinuity model thus allows us to propose some possible explanations for the dysfunctional interpretive and inferential thought processes of schizophrenics of the paranoid type, with the help of an additional model based on formal semantics (Musiol \& Rebuschi, 2011). On the other hand, it does not allow us to draw any conclusions about possible similar dysfunctions among schizophrenics of the disorganized type. We are therefore forced to acknowledge that, in the present state of our research, it is impossible to decide which of the following possibilities is correct: either the specific characteristics of verbal interactions between a disorganized schizophrenic patient and a "normal" interlocutor are not captured by the discontinuity model we developed, or these disorganized patients do not exhibit significant incoherency in their dialogue.

The question of what kind of process supports this sort of incoherence arises as soon as we compare the specificities of these incongruous or even incoherent behaviors with theoretical and interpretive models of congruent discourse, such as models of dialogical and pragmatic analysis. We hypothesize that the processes at stake are those underlying the comprehension and calculation of communicative intentions, in Sperber's sense of the term: "Comprehension (or its pragmatic layer) is an inferential process, using as input the output of linguistic decoding and aiming at discovering the speaker's meaning. Comprehension consists, therefore, in inferring a mental state (an intention of a specific kind) from behavior (an utterance)" (Sperber, 2000, p. 129).

Furthermore, we know that decisive verbal-interaction discontinuities have some highly specific proprieties (Musiol, 2002). They appeared here solely in the course of self-initiated conversational sequences (i.e., initiated by the patient). From this standpoint, our model is not only capable of accounting for defective processes that can be grasped in terms of actionplanning deficits, as in experimental cognitive neuropsychology for example, but is also and especially very effective for capturing dysfunctions affecting certain cognitive-inferential processes related to spared rationality. This capability is not offered by experimentation, questionnaires, or structured and semi-structured interviews, where the subject (here, the patient) is always in the "reactor's" position and is therefore led to react and adapt to the presentation of a "stimulus" present in the discourse of another person (e.g., in the task instructions given by an experimenter).

While no link was found here between the occurrence of non-decisive discontinuous transaction sequences and the clinical form of the schizophrenic interlocutor's pathology when the medication variable was not controlled, this was no longer true when we did control for this factor. For the schizophrenics who were not under any kind of antipsychotic treatment, we found more non-decisive discontinuities among patients of the disorganized type than among the paranoid ones. For those taking antipsychotic drugs, we found more 
non-decisive discontinuities among the paranoid schizophrenics than among the disorganized ones.

These results once again stress the merits of taking the medication variable into account in research into this disorder. Although we are not the first to make this recommendation, there are still few studies that look at the impact of medication on dialogue behavior (and not just verbal behavior) or on cognitive-inferential processes. Taking this type of variable into account has another advantage. It brings up the issue of the specificities of the cognitive processes underlying these disorders. Indeed, the present statistical results suggest that only the model of non-decisive discontinuity was able to bring out a significant effect of medication on the type of incoherence (Verhaegen \& Musiol, 2009), firstly in terms of a decrease in discontinuity, i.e., the reestablishment of certain forms of coherence solely for patients suffering from the disorganized type of schizophrenia, and secondly, in terms of an increase in discontinuity for the paranoid type of patient.

\section{Conclusion}

The present findings enable us to define communication disorders in a more precise way than was possible until the late 1980's when the term "pragmatic impairment" was used to mean the same thing as impaired language use. Today, the pragmatic approach in cognitive psychopathology addresses various theoretical and practical dimensions of cognitive psychology and neurocognition. From an empirical point of view, however, descriptions of certain characteristics of severe disorders (psychoses and neuropathologies) remain inadequate. For example, we still do not have a precise symptom-classification system for describing the interpretive and inferential thought disorders of patients.

Psychology studies that take a pragmatic approach attempt to grasp and formalize this type of cognitive activity, thereby putting this approach in a position to supply new knowledge, not only for defining "incoherence" but also for capturing it by relating data obtained in a pragmatic perspective to neurocognitive conceptions of schizophrenia (Musiol \& Verhaegen, 2009). The formal semantic approach should then allow us to gain new and better-informed insight into the psychocognitive processes associated with thought disorders (Musiol \& Rebuschi, 2011).

Our investigation strategy sheds light on the question of the extent to which clinicians can make valid intuitive judgments about a patient's language and/or communication deficiencies when faced with the patient's behaviors. An apparent communication deficiency of a schizophrenic patient may not imply a thought disorder (even if a thought disorder most likely means impaired communication). From the diagnosis standpoint, the pragmatic approach to cognitive psychopathology allows us to contemplate the possibility of clarifying or even operationalizing the notion of "formal thought disorder". In a general way, our investigation strategy contributes to advancing our understanding of language and communication in relation to schizophrenia (Crow, 2010; Titone, 2010).

\section{Acknowledgment}

We wish to thank Dr. Jean-Michel Durand (CHS Marius Lacroix, La Rochelle, France) and Dr. Philippe Brun (CH des Hauts-Clos, Troyes, France) for their help with data collection. Thanks are also extended to Vivian Waltz for her translation of this paper. 


\section{References}

Andreasen, N. C. (1979a). Thought, language and communication disorders. I-Clinical assessments definition of terms, and evaluation of their reliability. Archives of General Psychiatry, Vol. 36, pp. 1315-1324, ISSN 1538-3636

Andreasen, N. C. (1979b). Thought, language and communication disorders. II-Diagnostic significance. Archives of General Psychiatry, Vol. 36, 1325-1330, ISSN 1538-3636

Andreasen, N. C. (1982). Negative symptoms in schizophrenia. Archives of General Psychiatry, Vol. 39, 784-788, ISSN 1538-3636

Andreasen, N. C. (1983). Scale for the Assessment of Negative Symptoms (SANS), Iowa city, University of Iowa

Andreasen, N. C. (1984). Scale for the Assessment of Positive Symptoms (SAPS), Iowa city, University of Iowa

Andreasen, N. C., \& Carpenter, W. T. Jr. (1993). Diagnosis and classification of schizophrenia. Schizophrenia Bulletin, Vol. 19, pp. 199-214, ISSN 0586-7614

Andreasen, N. C., \& Grove, W. M. (1986). Thought, language, and communication in schizophrenia: Diagnosis and prognosis. Schizophrenia Bulletin, Vol. 12, 348-359, ISSN 0586-7614

Andreasen, N. C., \& Olsen, S. (1982). Negative versus positive Schizophrenia. Archives of General Psychiatry, Vol. 39, pp. 789-794, ISSN 1538-3636

Andreasen, N. C., Hoffman, R. E., \& Grove, W. M. (1985). Mapping abnormalities in Language and Cognition, In Controversies in schizophrenia: changes and constancies, A. Alpert (Ed.), pp. 199-226, Guilford Press, 978-089-8623-75-8, New York

American Psychiatric Association (1994). Diagnostic and statistical manual of mental disorders. Fourth Edition (DSM IV). American Psychiatric Association, ISBN 978-089-0420-62-1, Washington DC

Auchlin, A. (1988). Dialogue et stratégies: propositions pour une analyse dynamique de la conversation, In Echanges sur la conversation, J. Cosnier, N. Gelas, \& C. KerbratOrecchioni (Eds.), pp.33-45), Edition du CNRS, ISBN 978-222-2041-03-0, Paris

Bakhtine, M. (1930/1981). [V.N. Volochinov]. La structure de l'énoncé. In Mikhail Bakhtine, le principe dialogique, T. Todorov T (Ed.), pp. 287-316, Éditions du Seuil, 978-202-005830-8, Paris

Bazin, N., Lefrere, F., Passerieux, C., Sarfati, Y., \& Hardy-Bayle, M. C. (2002). Troubles formels de la pensée: traduction française de l'échelle d'évaluation de la pensée, du langage et de la communication (Scale for the Assessment of Thought, Language and Communication: TLC). L'Encéphale, Vol. 28, pp. 109-119, ISSN 0013-7006

Bazin, N., Sarfati, Y., Lefrere, F., Passerieux, C., \& Hardy-Bayle, M.C. (2005). Scale for the evaluation of communication disorders in patients with schizophrenia: A validation study. Schizophrenia Research, Vol. 77, N¹, pp. 75-84, ISSN 0920-9964

Berman, I., Viegner, B., Merson, A., Allan, E., Pappas, D., \& Green, A. I. (1997). Relationships between positive and negative symptoms and neuropsychological deficits in schizophrenia. Schizophrenia Research, Vol. 25, N¹, pp. 1-10, ISSN 0920-9964

Bleuler, E. (1911). Dementia praecox ou groupe des schizophrénies. E.P.E.L., G.R.E.C. French translation of 1993 ISBN 978-290-8855-11-1 
Chaïka, E. O. (1974). A linguist looks at 'schizophrenic' language. Brain and Language, Vol. 1, pp. 257-276, ISSN 0093-934X

Chaïka, E. O. (1990). Understanding psychotic speech: Beyond Freud and Chomsky, Charles C Thomas Pub Ltd, ISBN 978-039-8056-48-3, Illinois, USA.

Chapman, L. J., \& Chapman, J. P. (1989). Strategies for resolving the heterogeneity of schizophrenics and their relatives using cognitive measures. Journal of Abnormal Psychology, Vol. 98, N²4, pp. 357-366, ISSN 0021-843X

Chaslin, P. (1912). Groupe provisoire des folies discordantes. In Eléments de sémiologie et clinique mentales. Asselin et Houzeau, Paris

Crow, T. J. (1980). Molecular Pathology of schizophrenia: More than one disease process? British Medical Journal, Vol. 280, pp. 66-68, ISSN 0959-8138

Crow, T. J. (2010). The nuclear symptoms of schizophrenia reveal the four quadrant structure of language and its deficit frame. Journal of Neurolinguistics, Vol. 23, N¹, pp. 1-9, ISSN 0911-6044

Docherty, N.M., Cohen, A.S., Nienow, T.M., Dinzeo, T.J., \& Dangemaier, R.E. (2003). Stability of formal thought disorder and referential communication disturbances in schizophrenia. Journal of Abnormal Psychology, Vol. 112, pp. 469-475, ISSN 0021-843X

Frith, C. D. (1992). The cognitive Neuropsychology of Schizophrenia. LEA, ISBN 978-0863773341, Hove

Fromkin, V. A. (1975). A linguist looks at "a linguist looks at schizophrenic language". Brain and Language, Vol.2, pp. 498-503, ISSN 0093-934X

Goffman, E. (1974). Les rites d'interaction. Minuit, ISBN 2707300225, Paris

Goldberg, T. E. \& Weinberger, D. R. (1995). Thought disorder, working memory and attention: interrelationships and the effects of neuroleptic medications. International Clinical Psychopharmacology, Vol. 10, N³, pp. 99-104, ISSN 0268-1315

Goldstein, G. (1990). Neuropsychological heterogeneity in schizophrenia: A consideration of abstraction and problem solving abilities. Archives of Clinical Neuropsychology, Vol. 5, pp. 251-264, ISSN 0887-6177

Grice, H. P. (1975). Logic and conversation, In Syntax and Semantics 3: Speech Acts, P. Cole, \& J. L. Morgan (Eds.), pp.41-58, New York: Academic Press.

Grice, H. P. (1987). Conceptual analysis and the province of philosophy, In Studies in the way of words, H.P. Grice (Ed.), pp. 181-185, Harvard University Press, ISBN 9780674852716, Cambridge (MA), London.

Hardy-Bayle, M. C., Sarfati, Y., \& Passerieux, C. (2003). The cognitive basis of disorganization in schizophrenia and its clinical correlates: toward a pathogenetic disorganization scale. Schizophrenia Bulletin, Vol. 29, N³, pp. 459-471, ISSN 05867614

Harvey, P. D., Green, M. F., Mc Gurk, S. R., \& Meltzer, H. Y. (2003). Changes in cognitive functioning with risperidone and olanzapine treatment: a large-scale, double-blind, randomized study. Psychopharmacology, Vol. 69, pp. 404-11, ISSN 0033-3158

Harvey, P. D., Lombardi, J., Leibman, M., White, L., Parrella, M., Powchik, P., \& Davidson, M. (1996). Cognitive impairment and negative symptoms in geriatric chronic schizophrenic patients: a follow-up study. Schizophrenia Research, Vol. 22, N³, pp. 223-231, ISSN 0920-9964 
Hauser, M. D., Chomsky, N., \& Fitch, W. T. (2002). The Faculty of Language: What Is It, Who Has It, and How Did It Evolve?. Science, Vol. 298, pp. 1569-1579, ISSN 00368075

Heinrichs, R. W. (1993). Schizophrenia and the brain: conditions for a neuropsychology of madness. American Psychologist, Vol. 48, N³, pp. 221-233, ISSN 0003-066X

Kay, S. R., Fiszbein, A., \& Opler, L. A. (1987). The Positive and Negative Syndrome Scale (PANSS) for schizophrenia. Schizophrenia Bulletin, Vol. 13, pp. 261-276, ISSN 05867614

Kraepelin, E. (1919). Dementia Praecox and Paraphrenia. Trans. R. M. Barclay, \& G. M. Robertson (Eds.). Krieger RE, 1971, ASIN: B000OKQ154, New York.

Liddle, P. F. (1987). The symptoms of chronic schizophrenia. A re-examination of the positive-negative dichotomy. British Journal of Psychiatry, Vol. 151, pp. 145-151, ISSN 0007-1250

Liddle, P. F., Ngan, E. T. C., Caissie, S. L., Anderson, C. M., Bates, A. T., Quested, D. J., White, R., \& Weg, R. (2002). Thought and Language Index: an instrument for assessing thought and language in schizophrenia. British Journal of Psychiatry, Vol. 181, pp. 326-330, ISSN 0007-1250

McKenna, P. \& Oh, T. (2005). Schizophrenic speech. Making sense of Bathroots and Ponds that fall in doorways. Cambridge University Press. ISBN 978-052-1810-75-2, Cambridge

Meltzer, H. Y. \& McGurk, S. (1999). The effects of clozapine, ripseridone and olanzapine on cognitive function in schizophrenia. Schizophrenia Bulletin, Vol. 25, pp. 233-55, ISSN 0586-7614

Musiol, M. (1992). De l'incohérence du discours au désordre de la pensée chez le schizophrène. Psychologie Française, Vol. 37, pp. 221-233, ISSN 0033-2984

Musiol, M. (2002). Les conditions de l'analyse des troubles de la pensée dans l'interaction verbale (Contribution au programme pragmatique et cognitif en psychopathologie) [HDR]. Université Paris 8, Paris

Musiol, M. (2004). Les contrats de communication au risque des pathologies de la communication, In Psychologie sociale et communication, M. Bromberg, \& A. Trognon (Eds.), pp. 77-94, Dunod, ISBN 210007166, Paris

Musiol, M. \& Pachoud, B. (1999). Les conditions de l'interprétation psychopathologique des troubles du langage chez le schizophrène. Psychologie Française, Vol. 44, N²4, pp. 319-332, ISSN 0033-2984

Musiol, M. \& Rebuschi, M. (2011). From conversational analysis to a model of conceptual and referential thought. In Formal Approaches of dialog, A. Trognon (Ed.), PUN, ISBN 978-281-4300-42-2, Nancy, France

Musiol, M. \& Trognon, A. (2000). Eléments de Psychopathologie Cognitive. Le discours schizophrène, Armand Colin, ISBN 978-220-0015-69-5, Paris, France

Musiol, M. \& Verhaegen, F. (2002). Vers une stratégie de formalisation de la rupture dans l'interaction verbale. Philosophia Scientiae, Vol. 6, Nº1, pp.125-161, ISSN 1281-2463

Musiol, M. Verhaegen, F. (2009). Appréhension et catégorisation de l'expression de la symptomatologie schizophrénique dans l'interaction verbale. Annales MedicoPsychologiques, Vol. 167, 717-727, ISSN 0003-4487 
Olivier, V., Hardy-Bayle, M. C., Lancrenon, S., Fermanian, J., Sarfati, Y., Passerieux, C., \& Chevalier, J. F. (1997). Rating scale for the assessment of communication disorders in schizophrenics. European Psychiatry, Vol. 12, pp. 356-361, ISSN 0924-9338

Pachoud, B. (1996). Les troubles de la compétence interactionnelle dans la schizophrénie. In Raisons Pratiques (La folie dans la place), I. Joseph, \& J. Proust (Eds.), pp.211-230, Editions de l'Ecole des Hautes Etudes en Sciences Sociales, ISBN EHESS 2-71321218-9, Paris

Pike, K. (1967). Language in relation to unified theory of the structure of human behavior. Mouton, ISBN 978-902-7918-69-7, The Hague.

Politzer, G. (2002). Le raisonnement humain, Hermès, ISBN 2-7462-0501-7, Paris

Pollock, J. Y. (1997). Langage et cognition, PUF, ISBN 978-213-0480-90-7, Paris

Rips, L. J. (1995). Deduction and cognition. In An invitation to cognitive science: Thinking, E. E. Smith, \& D. N. Osherson (Eds.), pp. 297-343, MIT Press, ISBN 978-026-2650-43-4, Cambridge (Ma), London

Rochester, S. \& Martin, J. R. (1979). Crazy Talk. A Study of the Discourse of Schizophrenic Speakers, Plenum Press, ISBN 978-030-6402-36-4, London

Roulet, E., Auchlin, A., Moeschler, J., Rubattel, C. \& Schelling, M. (1985). L'articulation du discours en français contemporain, Peter Lang, ISBN, 978-326-1037-94-7, Berne

Searle, J. R. \& Vanderveken, D. (1985). Foundations of illocutionary logic, Cambridge University Press, ISBN 978-052-1108-85-0, Cambridge.

Sperber, D. (2000). Metarepresentations in an evolutionary perspective. In D Metarepresentations: An multidisciplinarity perspective, Sperber (Ed.), pp. 117-137, Oxford University Press, ISBN 978-019-5141-15-3, Oxford.

Sperber, D. \& Wilson, D. (1995). Relevance (2nd edition), Blackwell, ISBN 978-063-1198-78-9, Oxford/Cambridge.

Titone, D. (2010). Language, communication, \& schizophrenia. Journal of Neurolinguistics, Vol. 23, pp. 173-175, ISSN 0911-6044

Trognon, A. (1987). Débrayages conversationnels. DRLAV, Vol. 36-37, pp.105-122, ISSN 07549296

Trognon, A. (1992). L'approche pragmatique en psychopathologie cognitive. Psychologie Française, Vol. 37, pp.189-202, ISSN 0033-2984

Trognon, A. (1995). Structures interlocutoires. Cahiers de linguistique française, Vol. 17, pp. 7998, ISSN 0259-6199

Trognon, A. \& Musiol, M. (1996). L'accomplissement interactionnel du trouble schizophrénique. In Raisons Pratiques (La folie dans la place), I. Joseph, \& J. Proust (Eds.), pp.179-209, Editions de l'Ecole des Hautes Etudes en Sciences Sociales, ISBN EHESS 2-7132-1218-9, Paris

Trognon, A.; Musiol, M. \& Kostulski, K. (1999). Une théorie de la conversation est-elle possible? Verbum, Vol. XXI, N², pp. 133-146, ISSN 0182-5887

Tsuang, M. (2000). Schizophrenia: genes and environment. Biological Psychiatry, Vol. 47, pp. 210-220, ISSN 0006-3223

Verhaegen, F. \& Musiol, M. (2008). Impact des médicaments antipsychotiques sur les discontinuités du comportement verbal en conversation schizophrénique. Psychologie de l'interaction, Vol. 25-26, pp. 164-94, ISSN 1291-0600 
Verhaegen, F. \& Musiol, M. (2009). Symptomatologie schizophrénique et processus psychopharmacologiques: contribution empirique. Annales Medico-Psychologiques, Vol. 167, pp. 728-735, ISSN 0003-4487

Widlocher, D. \& Hardy-Bayle, M. C. (1989). Cognition and control of action in psychopathology. Cahiers de Psychologie Cognitive, Vol. 9, Nº6, 583-616, ISSN 02499185 


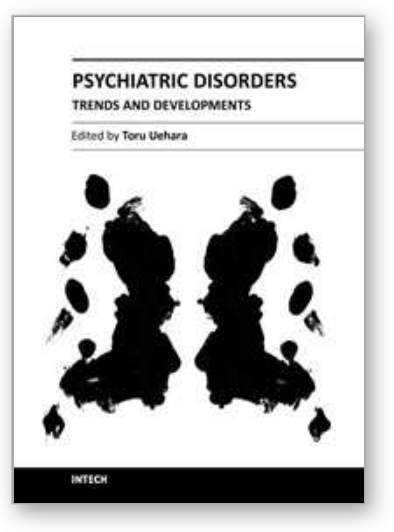

\author{
Psychiatric Disorders - Trends and Developments \\ Edited by Dr. Toru Uehara
}

ISBN 978-953-307-745-1

Hard cover, 514 pages

Publisher InTech

Published online 26, October, 2011

Published in print edition October, 2011

Due to their prevalence, pervasiveness and burden inflicted on men and women of today, psychiatric disorders are considered as one of the most important, sever and painful illnesses. This impairment of cognitive, emotional, or behavioural functioning is in some cases tragic. Aside from knowing the physical organic factors, such as infections, endocrinal illnesses or head injuries, the aetiology of psychiatric disorders has remained a mystery. However, recent advances in psychiatry and neuroscience have been successful in discovering subsequent pathophysiology and reaching associated bio-psycho-social factors. This book consists of recent trends and developments in psychiatry from all over the world, presented in the form of multifarious and comprehensive articles. The first two sections of the book are reserved for articles on schizophrenia and depression, two major illnesses present in this field. The third section of the book is reserved for addiction psychiatry, related not only to socio-cultural but also biological alterations. The last section of the book, titled Biological Neuropsychiatry, consists of three topics - updated molecular biology, fundamental neuroscience and clinical neuropsychiatric conditions. Doubtlessly, this book will be fruitful for future developments and collaboration in world psychiatry.

\title{
How to reference
}

In order to correctly reference this scholarly work, feel free to copy and paste the following:

Frederic Verhaegen and Michel Musiol (2011). Verbal Behavior Analysis as a Diagnostic and Psychopharmacological Strategy for Differentiating Paranoid and Disorganized Schizophrenics, Psychiatric Disorders - Trends and Developments, Dr. Toru Uehara (Ed.), ISBN: 978-953-307-745-1, InTech, Available from: http://www.intechopen.com/books/psychiatric-disorders-trends-and-developments/verbal-behavioranalysis-as-a-diagnostic-and-psychopharmacological-strategy-for-differentiating-para

\section{INTECH}

open science | open minds

\author{
InTech Europe \\ University Campus STeP Ri \\ Slavka Krautzeka 83/A \\ 51000 Rijeka, Croatia \\ Phone: +385 (51) 770447 \\ Fax: +385 (51) 686166 \\ www.intechopen.com
}

\author{
InTech China \\ Unit 405, Office Block, Hotel Equatorial Shanghai \\ No.65, Yan An Road (West), Shanghai, 200040, China \\ 中国上海市延安西路65号上海国际贵都大饭店办公楼 405 单元 \\ Phone: +86-21-62489820 \\ Fax: +86-21-62489821
}


(C) 2011 The Author(s). Licensee IntechOpen. This is an open access article distributed under the terms of the Creative Commons Attribution 3.0 License, which permits unrestricted use, distribution, and reproduction in any medium, provided the original work is properly cited. 